\title{
Seleção e Análise de Aplicativos Educacionais de Língua Portuguesa e de Matemática: Apropriação e Formação Docente
}

\author{
Rayssa A. Hitzschky ${ }^{1}$, Juliana S. Arruda ${ }^{2}$, Antônia Taticlé V. Cassiano ${ }^{1,}$ Cintia A. \\ Lima $^{1}$, Liliane Maria R. de Castro Siqueira ${ }^{1}$ \\ 1Instituto UFC Virtual - Universidade Federal do Ceará (UFC) \\ ${ }_{2}$ Universidade Estadual do Ceará (UECE). \\ \{hitzschkyrayssa, julianarruda24, taticlevieira, \\ arrucintia,lilianeramalho1609\}@gmail.com\}
}

\begin{abstract}
This study seeks to investigate actions of a workshop for teachers, through the selection and analysis of free educational applications in Portuguese and Mathematics, according to technical and pedagogical criteria. The workshop was organized in three moments: 1) Theoretical presentation; 2) Demonstration of an application in practice: Kahoot!; 3) Selection and analysis of educational applications. The main results point to the relevance of the formative moment for the appropriation, for the understanding and for the theoretical-practical application of the technical and pedagogical criteria during the use of resources. In addition, the resource analyzes show diverse and heterogeneous views, carrying the experiences and knowledge of the world of those who analyzed them.
\end{abstract}

Resumo. Este estudo busca investigar ações de uma oficina para docentes, por meio da seleção e da análise de aplicativos educacionais gratuitos de Língua Portuguesa e de Matemática, conforme critérios técnicos e pedagógicos. A oficina foi organizada em três momentos: 1) Apresentação teórica; 2) Demonstração de um aplicativo na prática: Kahoot!; 3) Seleção e análise de aplicativos educacionais. Os principais resultados apontam a relevância do momento formativo para a apropriação, para o entendimento e para a aplicação teórico-prática dos critérios técnicos e pedagógicos durante o uso dos recursos. Além disso, as análises dos recursos evidenciam olhares diversos e heterogêneos, carregando em si as vivências e os conhecimentos de mundo de quem os analisou.

\section{Introdução}

As Tecnologias da Informação e Comunicação (TIC) estão constantemente integradas aos campos das atividades humanas, em relação às ações de comunicação, socialização, trabalho e de aprendizagem. O conglomerado de informações disponíveis e as diversas formas de acessá-las refletem a integração de mídias que passam a coexistir no meio digital [Zednik et al. 2014]. Para Kenski (2003), as tecnologias transformam a comunicação, a cultura e a aprendizagem de grupos sociais. Toda aprendizagem, então, vem sendo mediada pelas tecnologias de cada período, por meio de interações entre pessoas e informações, gerando aprendizagens individuais e coletivas. 
Dentre as TIC, os dispositivos móveis demonstram uma forte presença na contemporaneidade, por meio da transposição de barreiras físicas e temporais, contribuindo para uma nova configuração do conhecimento. Sendo assim, "o acesso à informação tornou-se mais democratizado e dinâmico, fomentando o compartilhamento de saberes em tempo real e em diversas plataformas" [Hitzschky et al. 2016, p. 114].

A Base Nacional Comum Curricular (BNCC), de forma mais recente e complementar ao discurso dos Parâmetros Curriculares Nacionais (PCN), afirma que os alunos devem entender e utilizar tecnologias digitais "de forma crítica, significativa, reflexiva e ética nas diversas práticas sociais" [Brasil 2017, p. 9]. A BNCC ressalta, ainda, que é crucial para a escola, enquanto instituição formadora, o estímulo à "reflexão e à análise aprofundada e que contribua para o desenvolvimento de uma atitude crítica em relação ao conteúdo e à multiplicidade de ofertas midiáticas e digitais [Brasil 2017, p. 57].

Os dispositivos móveis estão cada vez mais presentes no ambiente escolar. Em contrapartida, alguns desafios são enfrentados pelos docentes em sala de aula, como limitações na formação inicial e continuada, falta de conhecimentos técnicos que auxiliem em demandas pedagógicas e problemas de infraestrutura e de legislação. A oferta de constantes formações docentes na escola pública torna-se necessária, visando a apropriação de conhecimentos da aprendizagem móvel e norteando diversas práticas pedagógicas. Nesse contexto, a questão desta pesquisa é a seguinte: Quais são as contribuições de uma formação de professores que abordou a seleção e a análise de aplicativos educacionais gratuitos de Língua Portuguesa e de Matemática?

Este estudo, fruto de um projeto de extensão, tem como objetivo geral analisar as contribuições de uma formação de professores que abordou a seleção e a análise de aplicativos educacionais gratuitos de Língua Portuguesa e de Matemática. Como objetivos específicos, propõe-se: 1) Averiguar os critérios técnicos e pedagógicos levantados pelos docentes durante a análise e a seleção dos aplicativos; 2) Observar os pontos positivos e negativos dos aplicativos destacados pelos professores no decorrer da seleção e da análise.

O estudo busca enriquecer o estado da arte que envolve a seleção e a análise de aplicativos educacionais realizada por professores, buscando apropriá-los e empoderá-los para o uso crítico desses recursos. Para que mudanças significativas sejam efetivadas em sala de aula, os aplicativos educacionais precisam ser estudados pelos docentes, para que eles conheçam as potencialidades destes recursos, utilizando-os em suas práticas.

\section{Referencial teórico}

Esta seção apresenta, primeiramente, a discussão sobre a aprendizagem móvel nas escolas. Em seguida, discute-se acerca dos dispositivos móveis e a formação docente.

\subsection{Os dispositivos móveis em contextos escolares: contribuições e desafios}

A utilização dos dispositivos móveis na sociedade fomenta discussões acerca da importância desses aparelhos para a dinâmica social, abrangendo a potencialidade desses recursos para o contexto escolar. As tecnologias móveis, por sua mobilidade e "por sua característica multimidiática, oportunizam a convergência de outras mídias, como imagem, áudio, vídeo, dentre outras, e ampliam as possibilidades pedagógicas" [Silva et al. 2015, p. 193]. 
A diversidade das atuais tecnologias móveis, encontradas em diferentes formatos, tamanhos e em constante evolução, demonstram que essas ferramentas evidenciam pontos de convergência em relação ao espaço-tempo. Dessa forma, elas trazem consigo aspectos favoráveis para o ensino e para a aprendizagem, por meio do veloz acesso às informações, da comunicação síncrona com outros aprendentes e docentes, além da colaboração propiciada por esses mecanismos de informação e de comunicação. Atualmente, os dispositivos móveis estão presentes em diferentes contextos formais e não formais de aprendizagem, nos quais é possível ultrapassar as barreiras físicas e temporais para o acesso à uma gama de conteúdos e informações. Desse modo, considera-se que a aprendizagem pode ocorrer em diferentes lugares, haja vista a versatilidade e a dinamicidade dos dias atuais [Unesco 2014].

As Diretrizes de Políticas para a Aprendizagem Móvel, concebidas pela Organização das Nações Unidas para a Educação, a Ciência e a Cultura (UNESCO), norteou o uso dos dispositivos móveis para fins educacionais, a nível mundial. Conforme o documento, considera-se que os aparelhos móveis são apontados como ferramentas utilizadas por alunos e professores em diversas situações para acessar informações, racionalizar o gerenciamento de tarefas diárias, além de facilitar a aprendizagem. Esse documento traz diretrizes, como: 1) fornecer apoio e formação a professores por meio de tecnologias móveis; 2) criar e aperfeiçoar conteúdos educacionais para uso em aparelhos móveis; 3) ampliar e melhorar as opções de conectividade e equidade; 4) desenvolver estratégias para acesso igual a todos; 5) promover o uso seguro e responsável das tecnologias móveis, dentre outras [Unesco 2014].

De acordo com Lucena (2016), os dispositivos móveis são fruto da cultura digital e da cibercultura, onde vivemos a mobilidade conectada a redes do tipo Wi-fi, WiMax e peer-to-peer. As tecnologias móveis, como smartphones, tablets e netbooks, podem ser carregadas para qualquer lugar, criando redes móveis de pessoas e tecnologias nômades localizadas em diferentes espaços geográficos. O crescimento dessas tecnologias propiciou o desenvolvimento de diversos aplicativos, possibilitando a interação entre linguagens: escrita, oral e hipermídia. "Esta outra forma de se expressar, de se comunicar e de produzir que mistura e remixa diferentes linguagens é a maneira utilizada pela atual geração de pessoas nascidas na era das tecnologias digitais" [Lucena 2016, p. 284].

A Base Nacional Comum Curricular (BNCC), documento normativo que apresenta as aprendizagens essenciais, reafirma as discussões em torno da dinamicidade e da multiplicidade das tecnologias digitais, incluindo as móveis. Acrescenta também que é papel da escola que "compreenda e incorpore mais as novas linguagens e seus modos de funcionamento, desvendando as possibilidades de comunicação (e de manipulação)" [Brasil 2017, p. 61].

Assim sendo, as orientações que indicam a inclusão dos dispositivos móveis nas escolas possibilitaram avanços no desenvolvimento de pesquisas. Segundo os estudos de Nascimento (2016), a disseminação e a globalização da Internet, e o consequente aumento no uso dos dispositivos móveis, oportunizam a formação de um novo cotidiano, essencialmente da juventude, que se adapta com mais facilidade a este uso. Ainda segundo a autora, os dispositivos móveis apresentam facilidade de acesso e de interação, possibilitando, portanto, diferentes formas de comunicação. As funcionalidades desses recursos podem facilitar o desenvolvimento de novas estratégias e metodologias para a práxis docente, viabilizando caminhos e olhares para as práticas pedagógicas. 


\subsection{Estudos empíricos sobre a formação de professores e o uso de dispositivos móveis: diálogos possíveis}

A realidade contemporânea trazida pelas tecnologias móveis constitui-se um meio que pode facilitar o desenvolvimento de diferentes estratégias nas metodologias e na prática docente. Os dispositivos móveis possibilitam aos docentes interesse, proporcionando uma reflexão crítica acerca de sua práxis e a utilização de recursos digitais. No entanto, apesar de provocar interesse, paralelamente, os docentes sentem-se inseguros por não terem a formação necessária para entenderem todas as funcionalidades incluídas e embutidas nos dispositivos móveis e seus recursos [Melo e Maia 2019].

Nesse contexto, Lima (2001) considera que a formação advinda dos cursos de graduação deve ser continuada. Assim, a extensão dos conhecimentos aprendidos na formação inicial deve ser aliada às práticas docentes e às suas vivências. $O$ desenvolvimento de um pensamento crítico e reflexivo acerca do contexto educacional e todos os fatores imbricados nesse processo podem ser bem explorados e enriquecidos por meio do uso de tecnologias digitais [Arruda et al. 2016]. Nesta conjuntura, os estudos de Moran (2010) discorrem sobre o uso dos dispositivos móveis dentro de um cenário de utilização e compreensão contextualizadas por parte dos professores, contudo, o essencial é a metodologia docente, ou seja, a prática deve incluir um propósito pedagógico. Nesse sentido, faz-se necessário repensar a práxis docente e suas intencionalidades, incluindo formações continuadas para aliar a utilização das tecnologias digitais ao planejamento, ao currículo e aos conteúdos.

Diante desse cenário, surge a necessidade em desenvolver formações docentes, buscando facilitar o entendimento dos professores em relação aos dispositivos móveis e suas possibilidades. $\mathrm{O}$ ambiente educacional e tecnológico anseia por atualizações e aprimoramentos docentes, englobando a dinamicidade e a inovação, além de estratégias e práticas originais em sua atuação profissional [Braga et al. 2018]. Pimentel (2013) considera que inovar as metodologias e todo o contexto didático são essenciais para a inserção dos recursos digitais ao longo dos processos de ensino e de aprendizagem. Sousa Júnior et al. (2017) consideram que as tecnologias móveis podem ser um instrumento da prática docente e das atividades dos alunos, cabendo destacar que esses recursos, em suas vivências, possibilitaram a criação de um ambiente interacional e pedagógico. Para que esse contexto seja constituído, é importante que haja organização e planejamento, por meio das potencialidades e funcionalidades dos recursos, ocasionando uma efetivação plena e concreta a partir do entendimento dos docentes.

As discussões e as reflexões teóricas em destaque, sobre a progressiva inquietação contemporânea acerca da formação do professor, proporcionam a necessidade de buscar análises e pesquisas sobre os conhecimentos que aparecem no contexto de ensino e de aprendizagem, processos que emergem a partir das interações entre docentes e discentes, perpassando também a constituição dos saberes docentes.

\section{Procedimentos metodológicos}

O presente estudo tem abordagem qualitativa e natureza descritiva. A pesquisa foi realizada no âmbito do projeto de extensão "Aprendizagem móvel e colaborativa no Ensino Fundamental", do Grupo de Pesquisa e Produção de Ambientes Interativos e Objetos de Aprendizagem (PROATIVA), da Universidade Federal do Ceará (UFC). A 
pesquisa é qualitativa, pois a fonte dos dados foi o ambiente natural, nos quais os investigadores estiveram em contato constante com os fenômenos investigados [Bogdan e Biklen 1991].

A oficina foi ministrada para 10 (dez) docentes da educação básica, com carga horária de 4 horas, sendo ofertada em novembro de 2019. A finalidade da oficina foi apropriar os professores para a escolha e para a análise de aplicativos educacionais voltados para as suas práticas pedagógicas cotidianas, com base em fundamentos técnicos e pedagógicos sólidos e fundamentados.

A oficina foi composta por três fases distintas. A primeira efetivou-se por meio de uma apresentação teórica, buscando apresentar os elementos que envolvem a utilização de dispositivos móveis no ambiente educacional, trazendo, assim, as Diretrizes da UNESCO para a Aprendizagem Móvel, além dos tipos de aplicativos educacionais observados durante os estudos do projeto de extensão e os critérios de seleção técnicos e pedagógicos aplicados. Estes critérios incluíram aspectos pedagógicos como: fundamentação pedagógica, conteúdo, feedbacks e níveis de dificuldade; os aspectos técnicos: usabilidade, funcionalidade e elementos audiovisuais. Como complemento, dois aplicativos e as suas informações específicas (metadados) foram apresentadas: Lele Silabas e Representar por Frações.

A segunda fase da oficina caracterizou-se pela observação in locus de um aplicativo com uma finalidade educacional, o Kahoot! Este aplicativo traz perguntas e respostas, em formato de quiz, no qual os usuários respondem às perguntas em tempo real e com um tempo estipulado. Ele é um recurso interativo, pois todos os usuários veem as respostas corretas no momento em que o tempo da pergunta se encerra, com um ranking ao final da partida. Ele foi utilizado para a sistematização das questões trabalhadas na apresentação teórica, de maneira demonstrativa e gamificada. Dessa forma, os professores responderam às perguntas, por meio dos seus smartphones conectados à Internet.

$\mathrm{Na}$ última fase, a equipe de formação propôs aos professores que se dividissem em grupos para um momento de "Reflexão sobre a ação". De forma colaborativa, os participantes selecionaram um aplicativo de Língua Portuguesa ou de Matemática, a partir dos critérios de seleção apresentados, apontando também aspectos positivos e negativos dos recursos escolhidos. Ao final, os grupos apresentaram as análises feitas, demonstrando uma proposta participativa e ativa que poderá ser utilizada futuramente com os alunos. Os instrumentos utilizados para a coleta dos dados foram observação participante, diário de campo, registros fotográficos, bem como conversas informais com os professores. No início e ao final do momento formativo, questionários on-line do Google Drive para sondagem do público e para a avaliação da oficina foram aplicados.

Dessa forma, as ações da pesquisa (Figura 01) foram assim organizadas: 1) Contextualização teórica inicial sobre os dispositivos móveis; 2) Demonstração de um aplicativo que, no momento, teve uma finalidade educacional (o Kahoot!); 3) Reflexão sobre a ação, a partir da seleção e da análise colaborativa dos aplicativos educacionais feitas pelos professores de acordo com os critérios técnicos e pedagógicos.

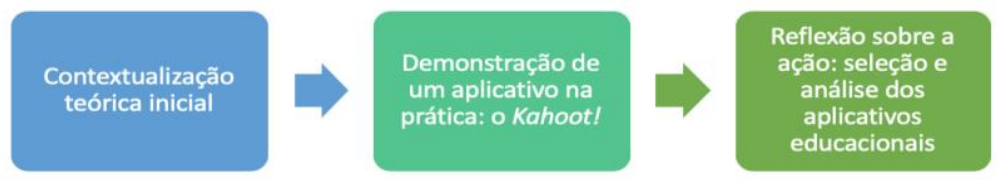

Figura 01. Ações da pesquisa 
Os percursos metodológicos, portanto, foram traçados a partir do entendimento de que o uso de aplicativos educacionais em práticas pedagógicas pode oferecer caminhos qualitativos quando aliados à formação docente. A utilização de aplicativos educacionais, desse modo, deve se sustentar no paradigma de que estes recursos devem ser compreendidos em sua totalidade pelos docentes, desde a sua escolha, seleção e utilização, buscando apropriá-los para este uso técnico-pedagógico em sala de aula.

\section{Resultados e discussões}

Os resultados deste estudo serão discutidos em três seções distintas. Primeiramente, será feita a análise do formulário de sondagem. Na segunda seção, será analisada a demonstração do Kahoot! entre formadores e participantes. Por último, será apresentada a análise colaborativa dos aplicativos educacionais selecionados feita pelos participantes.

\subsection{Análise do formulário de sondagem inicial e o uso das TIC em sala de aula}

Os resultados do formulário de sondagem inicial apontam que a maioria dos docentes $(62,5 \%)$ possui especialização e formação na área de Informática na Educação. Ressaltase que $100 \%$ dos professores participantes são da rede pública. Em relação aos momentos de utilização das tecnologias digitais no planejamento e na atuação educacional, 87,5\% dos participantes afirmam que utilizam as TIC para a estruturação dos seus planejamentos pedagógicos e $62,4 \%$ para desenvolver alguma atividade de trabalho.

Quando questionados a respeito do efeito das aulas com a utilização das TIC como recurso, $50 \%$ acreditam ser muito positivo e $50 \%$ ser positivo. Esses dados demonstram que os docentes consideram a relevância de uso das TIC em suas aulas. Mais especificamente, no que diz respeito à relação entre as TIC e a prática docente, $100 \%$ consideram que elas têm uma grande influência na aprendizagem dos alunos; $50 \%$ acreditam que elas desenvolvem as habilidades dos alunos no uso da Informática, capacitando-os para o trabalho, e apenas $12,5 \%$ afirmam não se aplicar à sua prática. Os dados revelam que a maioria dos docentes reconhece a utilização desses recursos em sua práxis, mas ainda há uma parcela que atua sem o uso das TIC.

\subsection{Análise da participação e interação docente a partir do aplicativo Kahoot!}

O aplicativo Kahoot! foi utilizado para a sistematização da apresentação teórica trabalhada no primeiro momento da oficina, de maneira demonstrativa e gamificada. As questões do aplicativo foram criadas anteriormente, a partir da apresentação e os professores tiveram um tempo limite de 40 segundos para responder às perguntas. Elas foram projetadas no quadro, um código foi repassado aos docentes e, assim, eles tiveram acesso às perguntas/respostas em seus smartphones conectados à Internet.

A partir dessa dinâmica, observou-se que apenas três professores conheciam o aplicativo proposto. Por conta disso, foi necessária uma orientação prévia quanto ao uso e os objetivos do jogo. A dinâmica possibilitou um momento rico e interativo, pois os docentes se mostraram motivados e engajados à medida que as perguntas eram apresentadas. O objetivo da dinâmica foi evidenciar um aplicativo na prática, no qual eles pudessem utilizar com os alunos em sala de aula. Muitos relataram que o utilizariam em suas práticas, após a explanação do conteúdo teórico ou para a revisão de uma temática. 
$\mathrm{Na}$ etapa subsequente, os professores foram convidados a participar do momento prático, que envolveu a seleção e a análise colaborativa de um aplicativo de Língua Portuguesa ou de Matemática, a partir dos critérios técnicos e pedagógicos apresentados.

\subsection{Reflexão sobre a ação: seleção e análise colaborativa de aplicativos educacionais a partir de critérios técnicos e pedagógicos}

Como momento prático da oficina, foi proposta uma atividade colaborativa de seleção e análise de aplicativos educacionais gratuitos feita pelos próprios professores. Em grupos, os participantes acessaram a Play Store e escolheram um aplicativo de Língua Portuguesa ou de Matemática, com base nos critérios de seleção/análise abordados na apresentação teórica. Em seguida, os grupos apresentaram os aspectos técnicos e pedagógicos do recurso, bem como os pontos positivos e negativos percebidos.

Os participantes dividiram-se em três grupos. Os aplicativos escolhidos foram: Português Coruja, voltado para a Língua Portuguesa e analisado pelos professores como sendo a partir do $5^{\circ} / 6^{\circ}$ ano do Ensino Fundamental e Photomath, direcionado para o ensino da Matemática, podendo ser utilizado desde o $4^{\circ}$ ano do Ensino Fundamental até o Ensino Médio. O aplicativo Português Coruja foi escolhido por dois grupos.

O primeiro aplicativo, Português Coruja (Figura 02), aborda temas como Ortografia, Concordância Verbal e Significação de vocábulos, por meio de um quiz. Além disso, o recurso apresenta comentários que retomam o assunto, propondo uma explanação significativa ao usuário acerca das normas gramaticais.

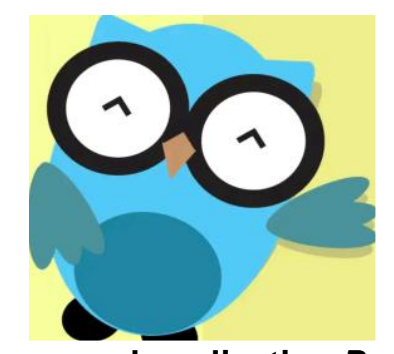

Figura 02. Imagem do aplicativo Português Coruja

O segundo aplicativo, Photomath (Figura 03), propõe a resolução de problemas matemáticos a partir das seguintes etapas: 1) captura da imagem do problema, por meio da câmera do dispositivo móvel; 2) leitura, por meio do reconhecimento dos números e dos símbolos matemáticos e; 3) solução do problema.

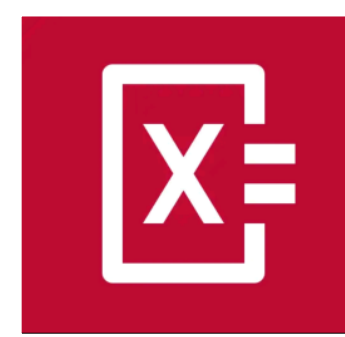

Figura 03. Imagem do aplicativo Photomath

Diante da análise feita pelos docentes, observou-se que os aplicativos analisados foram considerados recursos que apresentam contribuições pedagógicas significativas, pois os aplicativos foram considerados simples, objetivos e fáceis de utilizar. 
Para o aplicativo Português Coruja, o primeiro grupo considerou como aspectos pedagógicos relevantes a fundamentação pedagógica baseada na assimilação e no reforço, por meio de exercícios que trazem exemplos de diferenças ortográficas, sem "complicação". Além disso, os docentes consideraram o fato do aplicativo possuir níveis de dificuldade com desafios diversos, expostos de forma clara e objetiva. Paralelamente, os critérios técnicos levantados foram o fácil manuseio e os aspectos visuais e sonoros, facilitando, em geral, a sua utilização. Os docentes também destacaram a funcionalidade dos ícones e dos botões para a execução do aplicativo como razoável. Observa-se, assim, que todos os aspectos levantados pelos docentes em suas análises são elementos relevantes que devem ser considerados durante a seleção de um aplicativo educacional.

O segundo grupo que analisou o aplicativo Português Coruja considerou que o recurso foi criado conforme uma concepção pedagógica construtivista, pois os conteúdos são trabalhados em estágios e níveis de dificuldade. Para os professores, o formato do aplicativo em quiz proporciona o trabalho com os conteúdos de forma prática e objetiva. Os docentes complementam, ainda, que os feedbacks são imediatos e isso favorece a aprendizagem. Como critérios técnicos, segundo eles, o aplicativo é atrativo, rápido e de fácil uso, facilitando que os alunos utilizem o recurso durante as atividades propostas sem maiores dificuldades. Ressalta-se que o mesmo aplicativo foi analisado pelo primeiro grupo, porém os professores que o analisaram tiveram um outro olhar. Esse aspecto evidencia o quanto a análise de um aplicativo educacional é rica e heterogênea, carregando em si as vivências e os conhecimentos de mundo de quem o analisa.

O terceiro grupo analisou o aplicativo Photomath e elencou como critérios pedagógicos o fato do recurso ser interativo e ter como fundamentação o objetivo de identificar, resolver e explicar, passo a passo, as expressões numéricas para o aluno. Para os professores, o grande diferencial do aplicativo é a possibilidade do discente visualizar, em suas especificidades, as etapas de resolução de uma expressão numérica. Os docentes destacaram a ausência de feedbacks, em caso de dúvidas, como uma lacuna do aplicativo. Em relação aos critérios técnicos, o grupo destacou a usabilidade do aplicativo, de fácil uso, e a funcionalidade intuitiva dos botões, contudo, com poucos elementos visuais.

Dentre alguns pontos positivos ressaltados pelos docentes para os aplicativos analisados estão: a dinamicidade, uma vez que os recursos selecionados permitem trabalhar assuntos de Língua Portuguesa e de Matemática de maneira descomplicada e objetiva; a praticidade, visto que os aplicativos podem ser utilizados em ambientes formais e não-formais e, por fim, a eficiência, pois os aplicativos auxiliam na compreensão de aspectos linguísticos e na solução de problemas matemáticos.

Os pontos negativos encontrados pelos docentes compreenderam: uma abordagem ainda tradicional presentes nos aplicativos, tendo em vista os exercícios prontos em ambas as áreas e sem uma contextualização prévia do(s) assunto(s) tratado(s); dificuldades relacionadas à falta de controle por parte do professor referente às questões trabalhadas nos aplicativos; escassez ou ausência de elementos visuais, sonoros e feedbacks que, para os docentes, é um fator de engajamento durante a experiência com os aplicativos.

Diante disso, constatou-se que os docentes, de maneira unânime, aplicariam os conhecimentos discutidos e obtidos durante a formação em sua prática docente, tendo em vista as contribuições possibilitadas pelos aplicativos educacionais, bem como as vivências e os conhecimentos compartilhados e discutidos durante a oficina. Alguns depoimentos dos docentes revelam isso: "Foi importante para minha formação avaliar os 
recursos educacionais de aprendizagem para uso nas práticas docentes!" (Professor 1); "Todo material e oficina, apresentaram pontos positivos" (Professor 2). Essas afirmações corroboram com a perspectiva de que os aplicativos selecionados e analisados auxiliam em suas formações e na melhoria das metodologias e estratégias didático-pedagógicas.

Buscou-se, portanto, com esta pesquisa, aprofundar as discussões em torno do uso de aplicativos educacionais em práticas pedagógicas, a fim de delinear caminhos para a inserção destes recursos no ensino e na aprendizagem, por meio da formação docente. Objetivou-se, dessa forma, apresentar os pressupostos teóricos e práticos necessários para a compreensão acerca dos aplicativos educacionais pelos docentes.

\section{Considerações finais}

Este estudo concentrou-se em debates e pesquisas, objetivando analisar e discutir situações e vivências didáticas em torno da utilização de aplicativos educacionais, a partir de uma formação docente e, para isso, buscou-se responder à questão: Quais são as contribuições de uma formação de professores que abordou a seleção e a análise de aplicativos educacionais gratuitos de Língua Portuguesa e de Matemática?

Como principais resultados, observou-se que a vivência oferecida para os professores em oficinas, por exemplo, que envolvem o uso de dispositivos móveis e aplicativos educacionais no dia a dia da práxis docente, podem ser alternativas para a formação continuada, contribuindo para o aprimoramento de suas atuações.

Relacionando a análise aos estudos de Lucena (2016), Hitzschky et al. (2018) e Pimentel (2013), evidencia-se que a experiência de sala de aula aliada à formação acadêmica, paralelamente à interação entre os alunos e às formações continuadas, ajudam na constituição de novos saberes didáticos, como o uso de aplicativos educacionais, por meio do desenvolvimento da compreensão e da utilização teórico-prática.

O presente estudo levanta discussões sobre a relação entre a aprendizagem docente, a formação continuada e o uso de aplicativos educacionais, concluindo que as intervenções docentes sobre estes recursos podem levar a uma melhor compreensão dos conceitos intermediados pela aplicação das tecnologias digitais, auxiliando a práxis docente. Como estudos futuros, pensa-se em ampliar a investigação para outras áreas, possibilitando uma interação interdisciplinar com outros campos do conhecimento.

\section{Referências}

Arruda, J. S.; Siqueira, L. M. R. de. C.; Castro-Filho, J. A. (2016). "O uso das novas tecnologias na formação dos saberes da docência em professores do ensino fundamental. In: Congresso Regional sobre Tecnologias na Educação - Ctrl+e.

Brasil. Ministério da Educação. (2017). "Base Nacional Comum Curricular". Brasília: $\mathrm{MEC} /$ Secretaria de Educação Fundamental.

Bogdan, R.; Biklen, S. (1991). "Investigação qualitativa em educação: uma introdução à teoria e aos métodos". Portugal: Porto. 336p.

Braga, B. P. S.; Ferreira, A. L.; Gomes, A. V.; Araújo, L. C.; Vieira, M. C. L.; Brito, M. C. C.; Machado, Y. S. R. (2018). "Sala de Aula Invertida: Uma Proposta de Inovação Metodológica na Formação de Professores". In: CTRL+E, Fortaleza - III Congresso sobre Tecnologias na Educação. Fortaleza: Universidade Federal do Ceará, v. 2185. 
Hitzschky, R. A.; Arruda, J. S.; Lima, C. A.; Siqueira, L. M. R. de. C.; Castro-Filho, J. A. (2018). "O uso de aplicativos educacionais no Ensino Fundamental em tempos de aprendizagem móvel: contribuições para a formação de professores". Revista Tecnologias na Educação, Ano 10, n/vol.26, Edição Temática VIII - III Congresso sobre Tecnologias na Educação.

Hitzschky, R. A.; Brito, M. A. F.; Arruda, J. S.; Melo, M. B. O.; Castro-Filho, J. A. (2016). "Práticas educativas com o uso de dispositivos móveis em aulas de campo: aprendizagem para além dos muros da escola". In: I Congresso Regional sobre Tecnologias na Educação.

Lucena, S. (2016). "Culturas digitais e tecnologias móveis na educação". Educar em Revista, núm. 59, pp. 277-290.

Kenski, V. M. (2003). "Aprendizagem mediada pela tecnologia". Revista Diálogo Educacional, Curitiba, v. 4, n. 10, p. 47-56, set./dez.

Lima, M. S. L. (2001). “A formação contínua do professor nos caminhos e descaminhos do desenvolvimento profissional". Tese (Doutorado em Educação) - Faculdade de Educação, Universidade de São Paulo.

Melo, E. M.; Maia, D. (2019). "O Uso de Dispositivos Móveis para o Tratamento da Informação: uma Revisão Sistemática de Literatura". In: Congresso sobre Tecnologias na Educação (Ctrl+e). Anais do IV Congresso sobre Tecnologias na Educação. Porto Alegre: Sociedade Brasileira de Computação. p. 128-137.

Moran, J. M. (2010). "Os novos espaços de atuação do educador para a inovação". Inovação na Educação. In: Revista Aprendizagem, Paraná. IFPB, v. 2 n. 17, p. 62-63.

Nascimento, K. A. S. do. (2016). "MC-Learning: práticas colaborativas na escola com o suporte da tecnologia móvel". 256f. - Tese (Doutorado) - Universidade Federal do Ceará, Programa de Pós-graduação em Educação Brasileira, Fortaleza (CE).

Pimentel, N. M. (2013). "As políticas públicas para as tecnologias de informação e comunicação e educação a distância no Brasil". In Educação em foco, Juiz de Fora.

Silva, M. A; Nascimento, K. A. S; Carvalho, R. L; Maia, D. L. (2015). "O laptop educacional e o software educativo livre Geogebra no ensino de Matemática". In: Castro- Filho, J. A; Silva, M. A; Maia, D. (Org.). Lições do Projeto Um Computador Por Aluno: estudos e pesquisas no contexto da escola pública. Fortaleza: EdUECE.

Sousa Júnior, A., Oliveira, C., Braga, E. e Lima, V. A. (2017). "Google Suite for education: trazendo o Google Classroom como uma perspectiva para as salas de aula usando os dispositivos móveis". Anais do II Congresso sobre Tecnologias na Educação.

Unesco. (2014). "Policy Guidelines for Mobile Learning". Disponível em: $<$ http://unesdoc.unesco.org/images/0022/002277/227770por.pdf. Acesso: 01 Abr. 2020 .

Zednik, H.; Tarouco, L. M. R.; Klering, L.; García-Valcárcel, A.; Guerra, E. P. M. (2014). "Tecnologias digitais na educação: proposta taxonômica para apoio à integração da tecnologia em sala de aula". III Congresso Brasileiro de Informática na Educação. XXII Workshop de Informática na Educação. Dourados: MS. 